\title{
Toward Identification of the Sexual Killer: A Comparison of Sexual Killers Engaging in Post-Mortem Sexual Interference and Non-Homicide Sexual Aggressors
}

Sexual Abuse: A Journal of Research and Treatment

(C) The Author(s) 2015 Reprints and permissions: sagepub.com/journalsPermissions.nav DOI: I0.1।77/I0790632/5609935 sax.sagepub.com ๑SAGE

\section{Tamsin Higgs', Adam J. Carter², Ewa B. Stefanska³, and Emily Glorney ${ }^{4}$}

\begin{abstract}
Establishing a model of sexual assault reflecting psychosocial and behavioral characteristics of perpetrators of sexual killing and rape is necessary for development in risk assessment and intervention. Methodological variations in defining sexual killing have amalgamated serial and non-serial offenders and perpetrators with direct and indirect associations between killing and sexual arousal. This study defined sexual killing specifying that killing should be directly linked to sexual arousal, and sampled 48 sexual killers, operationalized to include only those engaging in post-mortem sexual interference, with one or two known female victims (non-serial), from prison service national (England and Wales) databases. These sexual killers were compared with 48 non-homicide, life or indeterminately sentenced sexual aggressors on psychological and crime scene characteristics. Contrary to previous research, fatal outcomes were associated with neither stranger victims nor weapon presence; sexual killing was characterized by severity of violence less so than non-fatal assault. Sexual killers more often reported problems with emotional loneliness, empathic concern, and
\end{abstract}

\footnotetext{
'University of Nottingham, UK

2National Offender Management Service, London, UK

3University of Birmingham, UK

${ }^{4}$ Royal Holloway, University of London, UK

\section{Corresponding Author:}

Tamsin Higgs, Doctoral Candidate (DForenPsy), University of Nottingham, YANG Fujia Building, Jubilee Campus, Nottingham, NG8 IBB, UK.

Email: tamsin.higgs@noms.gsi.gov.uk
} 
sexual entitlement than the sexual aggressors. Theoretical and applied implications are discussed.

\section{Keywords}

homicide, sexual killing, sexual aggression

Sexual killing is an unclearly defined phenomenon within the area of homicide research (Kerr, Beech, \& Murphy, 2013) and is not specified in law in the United States, Canada, the United Kingdom, and Germany where much of the research on sexual killing originates (Liem \& Pridemore, 2012; Oliver, Beech, Fisher, \& Beckett, 2007; Soothill \& Francis, 2012). Perpetrators of sexual killings are typically charged with murder or manslaughter (Liem \& Pridemore, 2012; Soothill \& Francis, 2012), and researchers widely utilize the criteria outlined in the early work by the Federal Bureau of Investigation (FBI) to classify a killing as sexual: "evidence or observations that indicate that the murder was sexual in nature" (Ressler, Burgess, \& Douglas, 1988, p. 8).

Indications that a homicide was sexual in nature are complicated because psychologically meaningful evidence that may not be obviously indicative of a sexual element could be overlooked if consideration is only given to physical evidence (e.g., Beech, Fisher, \& Ward, 2005). For example, in studies and reviews of the characteristics of sexual killing, strangulation is repeatedly found to be significantly associated with this type of crime (Beauregard \& Martineau, 2013; Carter \& Hollin, 2010; Häkkänen-Nyholm, Repo-Tiihonen, Lindberg, Salenins, \& Weizmann-Henelius, 2009; Kraemer, Lord, \& Heilbrun, 2004).

Incidences of sexual killing are relatively rare. In the United Kingdom, they are estimated at approximately $6 \%$ of all murders and manslaughters (Beech et al., 2005), and around $4 \%$ and $1 \%$ in Canada and the United States, respectively, equating to comparable annual rates of sexual killing per 100,000 people, given the much higher overall murder rates in the United States (Proulx, Cusson, \& Beauregard, 2007). However, difficulties in identifying sexual killing (e.g., where sexual motivations remain concealed; Folino, 2000) and the availability and reliability of information in defining cases of sexual killing (Clarke \& Carter, 2000; Schlesinger, 2007) mean that caution needs to be exercised in the interpretation of research (Maniglio, 2010).

Typologies and classifications of sexual killings have been put forward using different approaches depending on whether the focus of investigation was primarily concerned with criminal profiling, treatment and risk assessment, or theoretical advancement (Fisher \& Beech, 2007). Clinical and statistical descriptions of sexual killing have differentiated between types of sexual killers, identifying prototypical features and a range of motivational drives (Beech et al., 2005; Clarke \& Carter, 2000). Research has consistently indicated certain types of offenses within those labeled as sexual killing: sadistic, where absolute control or causing pain and suffering is central to the offense process; grievance driven or angry, in which sexual violence is not necessarily sexually motivated; and instrumental or other, in that the victim is killed in the 
commission of a sexual offense to be eliminated as a witness or dies subsequently to sexual assault as a result of injuries sustained (e.g., Chan \& Heide, 2009; Fisher \& Beech, 2007; Kerr et al., 2013).

In pursuit of a better understanding of perpetrators of sexual killing, scholars have searched for distinctive characteristics that demarcate these offenders from other types of sexual offenders. Research to determine whether sexual killers and sexual aggressors (specifically, perpetrators of rape or attempted rape) should be treated as two separate groups of sexual offenders has generally taken the approach of examining groups of sexual killers, and sometimes comparing them with sexual aggressors, on various background and developmental factors, personality characteristics, biological and neuropsychological markers, and offense and victim characteristics (e.g., Chéné \& Cusson, 2007; Nicole \& Proulx, 2007; Oliver et al., 2007; Proulx \& Sauvêtre, 2007). Langevin, Ben-Aron, Wright, Marchese, and Handy (1988) reported that transvestism and early development of sadism distinguished their sexual killer and sexual aggressor samples. In a more recent study, Langevin (2003) further reported sadism, fetishism, and voyeurism as characteristics of sexual killers. Koch, Berner, Hill, and Briken (2011) found sexual sadism as well as sexual dysfunction and personality disorder to be associated with sexual killers more so than sexual aggressors. In an analysis of sadistic crime scene behaviors, Healey, Lussier, and Beauregard (2013) found that rapists and sexual killers differed, in that the sadistic behaviors of killers were more likely to involve mutilation, whereas for rapists it appeared that arousal was achieved through verbal aggression, with a greater occurrence of humiliation.

With some consistency across studies, pre-crime anger and social and emotional isolation appear to be significant in the lead up to offending for sexual killers differentially to sexual aggressors (Grubin, 1994; Milsom, Beech, \& Webster, 2003). According to Grubin (1994), sexual killers may experience difficulty with appropriately expressing anger, which seems to be congruent with Chéné and Cusson's (2007) finding that anger in the lead up to the offense, but not during the attack, predicted killing as opposed to a non-fatal sexual assault. Langevin et al. (1988) also found general lifestyle anger to be much more characteristic of sexual killers than sexual aggressors or non-sexual killers, although it should be noted that the sample of sexual aggressors in this study excluded cases where there had been physical violence. With regard to social and emotional isolation, impoverished peer relationships particularly during crucial developmental periods are commonly reported by sexual killers (Grubin, 1994; Milsom et al., 2003; Nicole \& Proulx, 2007), with an emphasis on experiences suggesting rejection (perceived or actual) rather than internally attributed seclusion. This indicates that loneliness should be considered a possible precursor in the offense pathways of the perpetrators of this type of crime.

Aside from these points, overall there is little in the literature to determine whether there are strongly distinctive psychological characteristics for sexual killers and sexual aggressors. The view that the groups do not qualitatively differ is supported by Beech et al. (2005) who reported an absence of underlying schemas or worldviews that influence behavior unique to sexual killers. Furthermore, Salfati and Taylor (2006) compared the crime scene behaviors of sexual killers and sexual aggressors and found that 
both types of offenses mapped onto a single thematic framework of controlling behaviors, victim exploitation, and violence, but intensely violent behaviors were associated more frequently with sexual killing than with rape. This could be seen as supporting conceptualizations of rape and sexual killing that suggest these to be variants of sexual aggression in which fatal outcomes are largely situational (Beauregard \& Mieczkowski, 2012; Salfati \& Taylor, 2006). Specifically, the presence of a weapon during a sexual assault appears to increase the likelihood of a fatal outcome (Chéné \& Cusson, 2007; Mieczkowski \& Beauregard, 2010). Based on these findings, it has been proposed that sexual aggressors and sexual killers should best be conceptualized as occurring along a single continuum of sexual offending, in which the level of circumstantial violence within an attack is the critical factor determining whether the outcome is fatal (Oliver et al., 2007; Proulx et al., 2007; Salfati \& Taylor, 2006).

Of note with much of the research on sexual killing is that studies have tended to combine serial and non-serial killers (non-serial defined by Proulx et al., 2007, as killers of one or two victims without an emotional cool-off period; that is, two victims killed at the same time or closely together without opportunity for reflection differentiated from a "mass" killing in which several victims are killed in a single offense) within their sample of sexual killers. A systematic review by James and Proulx (2014) found sufficient differences between serial and non-serial sexual killers, suggesting that these groups should be studied separately and, in support of research attention focusing on non-serial killers, Campos and Cusson (2007) found that multiple victims are the exception rather than the norm among sexual killers. Furthermore, studies that do not include a control group should be interpreted cautiously in terms of comparability, as should the methods used to construct samples (Proulx et al., 2007), and previous researchers (Beauregard \& Martineau, 2013; Carter \& Hollin, 2010; Meloy, 2000) have highlighted limitations arising from small sample sizes and repetitive use of data.

Furthermore, despite the reasonably well-established angry and sadistic, and instrumental/other typologies, when making comparisons with non-homicide sexual aggressors, researchers almost invariably ignore these useful distinctions and design studies that categorize these perpetrators using the broad definitions encompassing all killings with a sexual element within a single group of sexual killers. However, the act of killing has a much different functional role depending on the particular type of offense. In some cases, there is a direct association between killing and sexual arousal. In other cases, killing is only indirectly linked to the sexual act, as in those examples of killing for elimination of the witness or the victim dies subsequently to a sexual assault perhaps even after the perpetrator has left the scene (Carter \& Hollin, 2014). The approach of studying samples including any type of sexual killing fails to distinguish between these direct and indirect links between killing and sexual arousal. Arguably, where there is an indirect link these offenders might not be expected to meaningfully differ from sexual aggressors because of the apparently highly circumstantial nature of the killing. Addressing potential confounding effects of sampling is important for achieving a better understanding of sexual killers.

One approach may be to examine only sexual killers where there is a direct link between killing and sexual arousal by isolating a behavior that is highly unlikely to 
occur in indirect cases. We propose that such a behavior could be post-mortem sexual interference, on the basis that this behavior could not occur without sexual arousal in the context of a killing. Post-mortem sexual interference offenders (PMSIOs) are defined by Carter, Mann, and Wakeling (2008) as sexual killers with one of the following characteristics:

The perpetrator disclosed that he had sexually assaulted the victim after killing them, there was evidence from a pathologist of post mortem sexual behavior, the perpetrator had disclosed post mortem sexual behavior, there was evidence of sex with an unconscious or dead victim or the perpetrator disclosed since conviction that they had sexually assaulted the victim after killing them. (p. 173)

As Carter et al. (2008) specified, PMSIOs are not necessarily necrophiles. Rather, although some PMSIOs may have necrophilic interests, necrophilia can be acted upon without perpetrating a killing, whereas in PMSIO a killing necessarily took place and sexual activity with an unconscious or dead victim occurred within a single psychological event (i.e., without an emotional cool-off period). For this reason, it could be said that there is a direct link between the act of killing and sexual arousal in these cases.

Clearly, post-mortem sexual interference is a proxy for the direct link that will result in a number of false negatives. Nonetheless, it may be a useful starting point, which does have some empirical support. Around half of those sexual killers driven by deviancy (i.e., more likely "direct" cases, as opposed to those driven primarily by anger, or those with purely instrumental reasons for killing subsequent to rape) engage in post-mortem sexual acts, and post-mortem mutilation occurs among deviancydriven sexual killers more so than in other types of sexual killers (Stefanska, Carter, Higgs, Bishopp, \& Beech, 2015).

Using this novel approach, the present study therefore aims to contribute to the theoretical understanding of the phenomenon of sexual killing, by comparing the crime scene and offender characteristics of a sample of PMSIOs with a sample of non-homicide sexual aggressors. Specifically, sexual aggressors where there was a history of sexual offending or an offense considered by the courts to warrant a more severe sanction, as this group of sexual aggressors are arguably the most relevant comparison group for the present study. That is, the groups could be considered comparable insofar as their offending is equally serious according to legal categorization. Furthermore, around a third of sexual killers have previous convictions for rape (Grubin, 1994; Oliver et al., 2007). Therefore, sampling sexual aggressors for comparison with sexual killers is problematic in that there is a reasonable probability that samples of sexual aggressors will contain offenders who will later perpetrate a sexual killing. By restricting the sample of sexual aggressors to include only those for whom there has already been maximum opportunity for their offending to escalate to sexual killing, there can be greater confidence that the sexual aggressor sample does not include perpetrators simply caught before they may have committed a sexual killing. 
The specific research question was to investigate whether sexual killers and sexual aggressors operationalized as described differ on crime scene and offender characteristics. The aim of this was to establish whether there are differences that delineate sexual killers from sexual aggressors, which previous research has possibly failed to detect due to the key methodological issue identified with the operationalization of terms.

\section{Method}

\section{Design}

A descriptive and comparative study was undertaken using data from National Offender Management Service (NOMS) records, pertaining to the entire prison population of England and Wales. ${ }^{1}$ The study aimed to determine whether crime scene and offender characteristics differentiate between sexual killers (operationalized for the purposes of this study to only include PMSIOs) and non-homicide sexual aggressors of women (perpetrators of rape or attempted rape).

\section{Sample}

The sample included only non-serial killers (one or two victims; Proulx et al., 2007), with female victims aged 14 years or above. Restricting the sample based on these victim characteristics improved the validity of the study, by offering consistency with previous research (Carter \& Hollin, 2010). A search of NOMS databases identified 918 offenders meeting these inclusion criteria, whose offenses were recorded as sexual killing using the criteria of a sexual element and/or sexual motivation that was evidenced, suspected, or admitted. These were cross-referenced with National Sex Offender Treatment Program (SOTP) databases to select only those who have attended the cognitive-behavioral SOTP in custody, and have thus completed treatment assessments and consented to the use of this information in national research conducted by the SOTP team. Referral to SOTP also ensured external validity to the sampling process, as a sexual element or motivation would necessarily have been identified from evidence gathered during the criminal investigation or subsequently disclosed by the offender. This yielded 220 cases, of which 70 were excluded because their psychometric data were substantially or entirely missing. The remaining 150 cases were checked against the Public Protection Unit Database (PPUD), which holds records such as presentence legal reports and offense summaries, coroner's reports, judges' sentencing remarks, and prison file information. These records were used to establish whether post-mortem sexual interference had occurred. The definition of post-mortem sexual interference provided by Carter et al. (2008) was used. The post-mortem interference behaviors of the sexual killer group included one or both of the following: (a) sexual acts (i.e., any post-mortem sexual activity except mutilation) or (b) sexual mutilation (i.e., of genital areas, to exclude cases where the body was cut up only for disposal purposes or set fire to destroy evidence). Given that the purpose of restricting the 
sample to include only these cases was not to study this behavior in itself but to increase the reliability of the sample as representative of cases where there was a direct link between sexual arousal and killing, cases were included if the victim was sexually assaulted so close to the time of death that it could not be certain that the victim was deceased when the sexual assault occurred, but there was evidence that they had, or were at least very likely to have lost consciousness. This screening process rendered a final sample of 48 cases of sexual killers who had engaged in post-mortem sexual interference.

The sample of sexual aggressors consisted of 48 men serving indeterminate prison sentences (imprisonment for life or imprisonment for public protection, release in both cases requiring approval from the Parole Board) for rape or attempted rape. These offenses carry indeterminate sentences depending on the severity of the index offense or due to a history of serious sexual offending. Therefore, the sample could be said to be a representative of sexual aggressors comparable with the sample of sexual killers in terms of the seriousness of their offending as recognized in law. That sexual aggressors in the present sample were serving indeterminate sentences indicates that they were likely to have previous sexual convictions ( $62.5 \%$ of the sexual aggressor sample had an offending history, including rape) but had not escalated in their offending from rape to sexual killing, increasing the validity of the sample. For further comparability with the sample of sexual killers, victims of the sexual aggressors were all adult females. All sexual aggressors serving an indeterminate sentence for offenses against adult female victims were identified from SOTP databases, and the dataset that was generated was used to case-by-case match against the sexual killers on their year of birth. Where an exact match was unavailable, the next closest match was accepted, so that there was no significant difference in the year of birth between the two samples, $t(94)=-1.04, p=.30$. All sexual killers and sexual aggressors included in the study were born between 1932 and 1981. Although the offenders' age at the time of the index offense (the murder/manslaughter or rape/attempted rape for which they received their indeterminate sentence) was not considered an appropriate variable to include in the matching criteria because the groups did not commit the same type of offense, it should be noted that the Mann-Whitney $U$ test showed that sexual killers were significantly younger at the time of the index offense $(M d n=24, n=48)$ than sexual aggressors $(M d n=36, n=48), U=329, z=-6.04, p<.01, r=.62$. According to PPUD information, the ethnicity of the samples was mostly White British; $93.8 \%(n=45)$ and $66.7 \%$ $(n=32)$ for sexual killers and sexual aggressors, respectively. The remainder of the sample of sexual killers were Black (Caribbean, African, or other Black background; $2.1 \%, n=1$ ), or other ethnicity (non-British White backgrounds, Mixed, Asian, or no ethnicity recorded; $4.2 \%, n=2$ ). The remainder of the sample of sexual aggressors were Black; $16.7 \%(n=8)$, or other ethnicity; $16.7 \%(n=8)$.

\section{Procedure and Measures}

Modus operandi (criminal event and behavioral characteristics associated with the offending process) were collated from PPUD. Evidence for each variable was scored 
dichotomously $(0=n o, 1=$ yes $)$ and managed within a coding framework developed by the authors informed by previous research (Beauregard \& Martineau, 2013; Salfati \& Taylor, 2006). Stranger victim was defined as someone that the offender had not previously met nor conversed with and as such neither offender nor victim could have recognized the other 24 hours before the offense (Thornton, 2007). A blitz attack was defined to capture cases where the victim was immediately overpowered, as opposed to a "con" approach which involved the offender gaining the victim's confidence and engineering a situation enabling them to offend, or a "situational" attack, meaning a consensual situation in which the victim was attacked perhaps following an argument, or having rejected sexual activity. Severity of violence aside from fatal injury was examined by analyzing the frequency of incidences of beating, multiple stab wounds, or other serious physical injuries (coded "high level of violence"). Precaution was defined by evidence that the perpetrator removed weapons from the crime scene or attempted to remove forensic evidence.

The first $10 \%$ of cases were blind coded by two of the authors with good strength of agreement (Cohen's $\kappa=.86$ ). For sexual aggressors who may have committed multiple sexual assaults, evidence was coded relating to their most recent offense. This was to allow for any escalation or refinement that may occur in an offender's behavioral pattern; the most recent case should be that during which the offender is performing an established pattern.

Cognitive and affective information was obtained from psychometric measures widely used in the assessment of sexual offenders because of their empirically established clinical relevance to sexual offenders' treatment needs and associated risk of reconviction (Wakeling, Beech, \& Freemantle, 2013). Data from assessments administered during initial SOTP group sessions were collated and included:

The Entitlement to Sex scale (Hanson, Gizzarelli, \& Scott, 1994): A nine-item measure scored on a 5-point Likert-type scale. Higher scores indicate greater endorsement of attitudes indicating a belief in an absolute entitlement to sex. Rallings and Webster (2001) assessed the scale to have adequate internal consistency $(\alpha=.65)$ and testretest reliability $(r=.67)$.

The Women are Deceitful scale has five items measuring beliefs that women are devious and manipulative (Offending Behavior Programmes Unit, 1995b). High scores (measured on a 5-point Likert-type scale) suggest endorsement of the aforementioned beliefs. The internal consistency is .79, and the test-retest reliability is .81, indicating good reliability (Rallings \& Webster, 2001).

The Locus of Control questionnaire (Levenson, 1974) scores 18 items on a 5-point Likert-type scale. Scores range from 0 to 72; those greater than 40 indicate attribution of experiences to internal factors, whereas low scores suggest a tendency to believe that experiences are determined by external factors outside of the individual's control. The measure has good internal consistency $(\alpha=.79)$ and test-retest reliability $(r=.87$; Rallings \& Webster, 2001).

The Revised Dissipation Rumination scale (Caprara, 1986; Wakeling \& Barnett, 2011) measures a tendency to ruminate angrily and bear grudges, using 15 dichotomous (yes/no) responses. Scores range from 0 to 30 with high scores indicating greater 
rumination. Wakeling and Barnett (2011) found the scale to have satisfactory internal consistency $(\alpha=.78)$ and adequate test-retest reliability $(r=.64)$.

Openness to Men and Women scales (Underhill, Wakeling, Mann, \& Webster, 2008) are each nine items, with responses on a 5-point Likert-type scale. Aptitude for establishing emotionally intimate relationships with men and women is reflected in high scores. The scales have good internal consistency at .85 and .86 , respectively, and satisfactory test-retest reliability at .86 and .81, respectively (Underhill et al., 2008).

The Self-Esteem scale (Webster, Mann, Thornton, \& Wakeling, 2007) measures general self-esteem using eight dichotomous (yes/no) items, with good internal consistency $(\alpha=.84)$ and test-retest reliability $(r=.90$; Webster et al., 2007).

The University of California Los Angeles Loneliness scale (UCLA; Russell, Peplau, \& Cutrona, 1980) is a 19-item measure, on a 4-point Likert-type scale. Items assess the extent to which respondents believe that they have meaningful relationships, have people close to them, or are lonely. Higher scores suggest fewer close, meaningful relationships and greater loneliness. The internal consistency of the UCLA is .95, and the test-retest reliability is .79 (Rallings \& Webster, 2001).

The Impulsivity scale (Eysenck \& Eysenck, 1978) has 13 items measuring tendency to act without thinking about long-term consequences. Rallings and Webster (2001) found the scale to have good internal consistency $(\alpha=.84)$ and test-retest reliability $(r=.79)$.

The interpersonal reactivity index (Davis, 1980) measures the cognitive and emotional components of empathy using a 5-point Likert-type scale, with separately scored subscales. Items measuring empathic concern (warmth, compassion, and concern for those in trouble or distress) have satisfactory internal consistency $(\alpha=.72)$ and testretest reliability $(r=.79)$; the internal consistency of the perspective taking subscale (which measures ability to see the point of view of others) is .72 with test-retest reliability of .81; and the Personal Distress subscale (high scores indicate difficulty coping with the distress of others) has internal consistency of .74 and test-rest reliability of .74 (Rallings \& Webster, 2001).

The Rape Myths scale (Offending Behavior Programmes Unit, 1995a) has 17 items, with high scores suggesting acceptance of justifications for rape. The scale has good psychometric properties $(\alpha=.83 ; r=.85$; Rallings $\&$ Webster, 2001).

\section{Analytical Strategy}

The first stage of the analysis looked at the modus operandi of sexual killers and sexual aggressors, to determine whether there are patterns of behavior more strongly associated with either group. The method used to kill the victim represents an important feature of the modus operandi of sexual killers; however, there can be no comparison with the modus operandi of sexual aggressors on these variables. Therefore, frequencies of the fatal injuries inflicted by sexual killers and the post-mortem interference behaviors recorded were calculated to describe the offense characteristics of the sample, before the remaining modus operandi variables were compared with those of the sexual aggressors, using chi-square tests for independence. 
Table I. Fatal Injuries Inflicted by Sexual Killers $(n=48)$ and Post-Mortem Interference Behaviors.

\begin{tabular}{lcr}
\hline & $n$ & $\%$ \\
\hline Fatal injury inflicted & 3 & 6.3 \\
Beating & 7 & 14.6 \\
Stabbing & 18 & 37.5 \\
Strangulation (manual) & 15 & 31.3 \\
Strangulation (ligature) & 4 & 8.3 \\
Asphyxiation & 1 & 2.1 \\
Other & & \\
Post-mortem & 39 & 81.3 \\
Sexual activity & 10 & 8.3 \\
Sexual mutilation & 4 & 8.3 \\
Biting (post-mortem only) & 4 & \\
Weapon only used during post-mortem & & \\
\hline
\end{tabular}

The psychometric data were collated and data distributions were analyzed for each sample independently, accepting data with skew and kurtosis $z$ scores $<1.96$ as normally distributed. Logarithm transformations were performed for data violating normality assumptions; however, this did not improve skewness sufficiently, therefore in these instances non-parametric tests were used on the untransformed data. The groups were compared using independent-samples $t$ tests and Mann-Whitney $U$ tests.

Finally, to understand not only whether the groups differed in terms of how extreme their scores were on psychometric measures, it was also considered useful to determine whether particular areas were more commonly problematic among either group. Scores were therefore normalized against the means and standard deviations for each scale taken from a control sample of untreated, low-risk (as measured by the RM2000; Thornton, 2007) sexual offenders drawn from SOTP databases. Scores greater or lesser (depending on the measurement direction of the scale) than the control sample by 1 standard deviation were recoded to create dichotomous "problem" or "no problem" scores. Chi-square tests of independence were carried out for each scale.

\section{Results}

The results of the first stage of the analysis looking at the frequencies of fatal injuries inflicted by sexual killers and the post-mortem interference behaviors that these perpetrators engaged in are presented in Table 1. Full profiles of the modus operandi variables that were analyzed for sexual killers and sexual aggressors are presented in Table 2. Results are significant at $p<.003$ applying a Bonferroni adjustment for multiple tests; however as this may overinflate the risk of Type II error (Perneger, 1998), results are presented assuming a conventional alpha level of .05 . The phi coefficient was used as a measure of effect size for 2 by 2 tables. For larger cross-tabulations, Cramer's $V$ is reported. 
Table 2. Modus Operandi Characteristics of Sexual Killers and Sexual Aggressors (\% in Parentheses; $N=96$ ).

\begin{tabular}{|c|c|c|c|c|c|c|c|}
\hline \multirow[b]{2}{*}{ Stranger victim } & \multicolumn{2}{|c|}{ Sexual killers } & \multicolumn{2}{|c|}{$\begin{array}{c}\text { Sexual } \\
\text { aggressors }\end{array}$} & \multirow{2}{*}{$\frac{\chi^{2}}{7.05}$} & \multirow{2}{*}{$\begin{array}{l}P \\
.008\end{array}$} & \multirow{2}{*}{$\begin{array}{c}\begin{array}{c}\text { Effect } \\
\text { size }\end{array} \\
0.27\end{array}$} \\
\hline & 17 & $(35.4)$ & 30 & $(62.5)$ & & & \\
\hline Approach & & & & & 9.25 & .01 & 0.31 \\
\hline Con & 15 & $(31.3)$ & 20 & $(4 I .7)$ & & & \\
\hline Blitz & 14 & $(29.2)$ & 22 & $(45.8)$ & & & \\
\hline Situational & 19 & $(39.6)$ & 6 & $(12.5)$ & & & \\
\hline Use of weapon during attack & & & & & 4.30 & .51 & 0.21 \\
\hline No weapon used & 29 & $(60.4)$ & 28 & $(58.3)$ & & & \\
\hline Knife & 10 & $(20.8)$ & 14 & $(29.2)$ & & & \\
\hline Firearm or imitation firearm & I & $(2.1)$ & 2 & $(4.2)$ & & & \\
\hline Axe & 0 & $(0.0)$ & 1 & $(2.1)$ & & & \\
\hline Bludgeon & 3 & $(6.3)$ & I & $(2.1)$ & & & \\
\hline Other (e.g., scissors/pan) & 5 & $(10.4)$ & 2 & $(4.2)$ & & & \\
\hline Restraints and/or gagging & 9 & $(18.8)$ & 8 & $(16.7)$ & .07 & .79 & 0.03 \\
\hline High level of violence & 14 & $(29.2)$ & 25 & $(52.1)$ & 5.23 & .02 & 0.23 \\
\hline \multicolumn{8}{|l|}{ Sexual acts } \\
\hline Vaginal penetration & 29 & $(60.4)$ & 42 & $(87.5)$ & 9.14 & .003 & 0.31 \\
\hline Anal penetration & II & $(22.9)$ & 12 & $(25.0)$ & .06 & .81 & 0.02 \\
\hline Digital penetration & 4 & $(8.3)$ & 13 & $(27.1)$ & 5.79 & .02 & 0.25 \\
\hline Other (e.g., masturbation) & 6 & $(12.5)$ & 5 & $(10.4)$ & .10 & .75 & 0.03 \\
\hline Humiliation & 1 & $(2.1)$ & 20 & $(4 I .7)$ & 22.00 & $<.001$ & 0.48 \\
\hline Biting ${ }^{\mathrm{a}}$ & 5 & $(10.4)$ & 2 & $(4.2)$ & & .44 & 0.12 \\
\hline Premeditation & 25 & $(52.1)$ & 37 & $(77.1)$ & 6.56 & .01 & 0.26 \\
\hline Precaution & 26 & $(54.2)$ & 3 & $(6.3)$ & 26.14 & $<.001$ & 0.52 \\
\hline Other meaningful behaviors & 10 & $(20.8)$ & 6 & $(12.5)$ & 1.20 & .27 & 0.11 \\
\hline Intoxication & 29 & $(60.4)$ & 28 & (58.3) & .04 & .84 & 0.02 \\
\hline
\end{tabular}

Note. Bonferroni adjusted $p=.003$.

aFisher's exact test used.

Some similarities and differences are noteworthy in the modus operandi of sexual killers and sexual aggressors. Victims were aged between 14 and 87 years, with no significant difference in the age of the victims of sexual killers $(M d n=28, n=48)$ and sexual aggressors $(M d n=25, n=42), U=841.5, z=-1.35, p=.18, r=.14$. Sexual aggressors were more likely than sexual killers to target a stranger victim, $\chi^{2}(1, N=96)=7.05, p=$ .008 , phi $=.27$, in a blitz attack, $\chi^{2}(2, N=96)=9.25, p=.01$, phi $=.31$.

Sexual killers were equally as unlikely as sexual aggressors to use a weapon during their attack, $\chi^{2}(5, N=96)=4.30, p=.51, V=.21$. Furthermore, the variable "high level of violence" showed that the assaults endured by the rape victims were more violent than those suffered by the victims of the sexual killers, $\chi^{2}(1, N=96)=5.23, p=.02$, phi $=.23$. Sexual killers sexually assaulted their victims vaginally with lower 
frequency than did sexual aggressors, $\chi^{2}(1, N=96)=9.14, p=.003$, phi $=.31$. Few cases of biting were found among either group, whereas humiliating acts were evident more frequently among rapists than among sexual killers, $\chi^{2}(1, N=96)=22.00, p<$ .001 , phi $=.48$. Sexual killers took more precautions than sexual aggressors to avoid detection, $\chi^{2}(1, N=96)=26.14, p<.001$, phi $=.52$. A small number of both groups engaged in other psychologically meaningful acts. For example, the sexual killers arranged the body in a deliberate way, set fire to the body with a suggestion that this was functionally significant rather than purely to destroy evidence, or re-dressed the body before leaving the scene. The sexual aggressors held the victim captive for extended periods or attempted reconciliatory acts such as helping the victim home, $\chi^{2}(1, N=96)=1.20, p=.27$, phi $=.11$.

The analysis of psychometric data found significant differences in scores for emotional loneliness and empathic concern. Sexual killers' emotional loneliness scores $(M=50.94, S D=13.54)$ were higher than sexual aggressors' $(M=40.51$, $S D=13.25), t(83)=3.6, p<.01$, with a large effect size in the difference in these scores $\left(\eta^{2}=.14\right)$. A small effect was found in differences in empathic concern scores, with sexual killers' scores $(M d n=19, n=47)$ being lower than sexual aggressors' $(M d n=21, n=48), U=775.5, z=-2.63, p<.01, r=.27$, meaning that sexual killers had lower empathic concern than sexual aggressors. Furthermore, not only do sexual killers experience more extreme emotional loneliness, but this is also a more widespread problem among the group than for sexual aggressors, $\chi^{2}(1, N=85)=5.89, p=.02, \mathrm{phi}=.26$. Also, significantly more sexual killers than sexual aggressors hold problematic (i.e., scoring at a level indicative of a treatment need) sexual entitlement beliefs, $\chi^{2}(1, N=94)=5.39, p=.02$, phi $=.24$, although as a group they do not score significantly higher on this measure than sexual aggressors $(M d n=9, n=46 ; M d n=8, n=48), U=948.5, z=-1.18, p=$ $.24, r=.12$. That is, sexual entitlement beliefs are not more extreme among sexual killers but the presence of these beliefs is found more often among the group than within the sexual aggressor group. Results of all psychometric data analyses are presented in Table 3.

\section{Discussion}

By drawing comparisons with offenders convicted for rape or attempted rape, receiving a life or indeterminate sentence (sexual aggressors), distinct psychological characteristics of sexual killers were identified. For example, the patterns of offending behavior emerged within a context of greater social disconnection. Consistent with previous research (Grubin, 1994; Milsom et al., 2003; Nicole \& Proulx, 2007), emotional loneliness was an important antecedent. Other contributing factors to sexual killing were problematic peer relationships, a lack of warmth toward others, low empathic concern, and sexual entitlement beliefs. Although few differences between sexual killers and sexual aggressors have so far been identified (e.g., Oliver et al., 2007), these findings may be indicative of a psychological profile of sexual killers distinct from sexual aggressors. 
Table 3. Comparison of Sexual Killers' and Sexual Aggressors' Mean/Median Scores on Psychometric Measures, and Number of Each Group Scoring at Least I Standard Deviation in the Undesired Direction Away From Normative Scores (\% in Parentheses; $n=48$ ).

\begin{tabular}{|c|c|c|c|c|c|c|c|c|c|c|c|c|c|c|c|}
\hline \multirow{4}{*}{$\begin{array}{l}\text { Psychometric scale } \\
\text { Self-esteem }\end{array}$} & \multicolumn{8}{|c|}{ Between-groups comparisons } & \multicolumn{7}{|c|}{ Comparisons with normative scores } \\
\hline & \multicolumn{2}{|c|}{$\begin{array}{l}\text { Sexual } \\
\text { killers }\end{array}$} & \multicolumn{2}{|c|}{$\begin{array}{c}\text { Sexual } \\
\text { aggressors }\end{array}$} & \multirow[b]{2}{*}{$t$} & \multirow[b]{2}{*}{$p$} & \multirow[b]{2}{*}{$\eta^{2}$} & & \multirow{2}{*}{\multicolumn{2}{|c|}{$\begin{array}{l}\text { Sexual } \\
\text { killers }\end{array}$}} & \multirow{2}{*}{\multicolumn{2}{|c|}{$\begin{array}{c}\text { Sexual } \\
\text { aggressors }\end{array}$}} & \multirow[b]{2}{*}{$\chi^{2}$} & \multirow[b]{2}{*}{$p$} & \multirow[b]{2}{*}{ Phi } \\
\hline & $M$ & $S D$ & $M$ & $S D$ & & & & & & & & & & & \\
\hline & 9.46 & 5.36 & 10.79 & 4.81 & 1.28 & .20 & .02 & & 14 & $(29.2)$ & 10 & $(20.8)$ & .89 & .35 & .10 \\
\hline Impulsivity & 9.23 & 8.45 & 8.66 & 7.62 & .35 & .73 & .00 & & 15 & $(31.9)$ & 12 & $(25.5)$ & .47 & .49 & .07 \\
\hline Perspective taking ${ }^{\mathrm{b}}$ & 16.36 & 5.47 & 18.4 & 5.43 & 1.82 & .07 & .03 & & 15 & $(31.9)$ & 9 & $(18.8)$ & 2.18 & .14 & .15 \\
\hline Locus of control & 48.81 & 7.84 & 50.31 & 8.4 & .90 & .37 & .01 & & 5 & $(10.4)$ & 7 & $(14.6)$ & .38 & .54 & .06 \\
\hline Women are deceitfulc & 6.26 & 4.01 & 6.38 & 3.7 & .14 & .89 & .00 & & 6 & $(13)$ & 5 & $(10.4)$ & .16 & .69 & .04 \\
\hline \multirow[t]{2}{*}{ Emotional loneliness ${ }^{d}$} & 50.94 & 13.54 & 40.51 & 13.25 & 3.6 & .001 & .14 & & 18 & $(42.9)$ & 8 & $(18.6)$ & 5.89 & .02 & .26 \\
\hline & Mdn & & $M d n$ & & $U$ & $p$ & $z$ & $r$ & & & & & & & \\
\hline Rumination $^{e}$ & 6 & & 6 & & $1,046.5$ & .79 & -.27 & .02 & 9 & $(19.1)$ & II & $(23.9)$ & .31 & .58 & .06 \\
\hline Empathic concern ${ }^{\mathrm{b}}$ & 19 & & 21 & & 775.5 & .008 & -2.63 & .27 & 15 & $(31.9)$ & 7 & $(14.6)$ & 4.01 & .05 & .21 \\
\hline Personal distress ${ }^{b}$ & 12 & & 10 & & 796 & .01 & -2.48 & .25 & 13 & $(27.7)$ & 8 & $(16.7)$ & 1.68 & .20 & .13 \\
\hline Open to women ${ }^{f}$ & 25 & & 26.5 & & 841 & .07 & -1.85 & .19 & 9 & $(20)$ & 5 & $(10.4)$ & 1.67 & .20 & .13 \\
\hline Open to menc & 21.5 & & 25 & & 871.5 & .08 & -1.76 & .18 & 14 & $(30.4)$ & 6 & $(12.5)$ & 4.51 & .03 & .22 \\
\hline Sexual entitlement ${ }^{c}$ & 9 & & 8 & & 948.5 & .24 & -1.18 & .12 & 9 & $(19.6)$ & 2 & $(4.2)$ & 5.39 & .02 & .24 \\
\hline Rape myths ${ }^{c}$ & 9 & & 7.5 & & 993 & .40 & -.84 & .09 & 4 & $(8.7)$ & 4 & (8.3) & .00 & .95 & .01 \\
\hline
\end{tabular}

Note. Bonferroni adjusted $p=.004$.

aSexual killers, $n=47$; sexual aggressors, $n=47$.

bSexual killers, $n=47$.

'Sexual killers, $n=46$.

dSexual killers, $n=42$; sexual aggressors, $n=43$.

eSexual killers, $n=47$; sexual aggressors, $n=46$.

fSexual killers, $n=45$.

The greater prevalence of sexual entitlement among sexual killers may be indicative of specific processes that would be important to understand in forensic case formulation. For example, sexual entitlement beliefs mediate the relationship between a sense of masculinity and sexually abusive attitudes and behaviors (Hill \& Fischer, 2001). It might be that masculinity is threatened among men who experience intense loneliness, which could be relevant in the development of sexually entitled thinking. Cognitive distortions and emotional loneliness may be the result of a failure to form emotionally intimate relationships and might represent learned protective strategies in response to rejection, or alternatively, attitudes and schemas may have impaired social functioning and inhibited social interaction. However, to achieve these theoretical and clinical objectives it is first important to clarify whether it is necessary to differentiate between direct and indirect cases of sexual killing, and the findings of this study suggest that is the case.

Distinctions were made in the situational factors of offenses. In this study, sexual killers gained the victim's trust and manipulated their way into her home, or became violent following an argument, sexual rejection, or sexual inadequacy in the context of 
an initially reciprocal interaction. These factors were atypical for sexual aggressors. Contrary to Chéné and Cusson's (2007) sexual crime fatality predictors, in the present study, sexual killers typically knew their victim and were unarmed; sexual aggressors were more likely to attack a stranger and to use a knife. It is possible that the targeting of strangers by the sexual aggressors was typical of the unique study subgroup of sexual aggressors, for whom a specific victim was perhaps not a salient factor in their offending. For example, rapists who use sexual violence explosively as an expression of anger (e.g., Beech, Ward, \& Fisher, 2006; Gebhard, Gagnon, Pomeroy, \& Christensen, 1965; Knight \& Prentky, 1990) or opportunistic sexual aggressors for whom antisocial cognitions and behavioral patterns permit impulsive acts of sexual violence in a range of different situational contexts (e.g., Gebhard et al., 1965; Knight \& Prentky, 1990).

Given that rape is typically committed against known victims (e.g., Macdowall et al., 2013), cautious interpretation of the present finding is necessary. Revisiting the criteria used to determine whether victims were known or strangers, that is, that neither offender nor victim could have recognized the other $24 \mathrm{hr}$ beforehand (Thornton, 2007), it is clear that the types of relationships possible between a perpetrator and a known victim are varied, and that there is not always a clear distinction between a known and stranger victim. Indeed, definitions of stranger vary across studies and are not always explicit (Carter \& Hollin, 2010). Cases involving specific victim selection, where stalking or targeting of an individual has occurred, would be considered as known victim in the present study, even though there may not be any reciprocal relationship between perpetrator and victim. Frequently, the victims of sadistic sexual killers are targeted in an attempt to satisfy deviant sexual fantasies (Beauregard \& Proulx, 2002). The data are not presently available to explore this further, but if similar behaviors were occurring in the sexual killers sampled here this may have inflated the rate of known victims within the group. From another perspective, it might be that the prevalence of stranger victims among sexual killers is in fact greater than the prevalence of stranger victims among sexual aggressors not limited to the samples selected for this study. Alternatively, it may be necessary to consider that the targeting of strangers should only be expected for specific subtypes of sexual killers. Further research will be necessary to establish whether amalgamating different types of sexual killers into a single group overinflates the prevalence of stranger victims in this type of crime if, as it has been argued, the typical operationalization of sexual killing is too broad.

In some cases of sexual killing where knives were present, there was no evidence of cutting or stabbing while the victim was alive but the knife appeared to have been used exclusively post-mortem. The offender may have brought the knife to gain compliance, inflicting post-mortem injuries in a heightened angry state, or it may be that mutilation reflects the acting out of elaborate deviant fantasies, commonly reported in research concerning the etiopathogenesis of sexual killing (Maniglio, 2010). Rather than using weapons to kill, most sexual killers strangled their victim. It could be argued that strangulation occurs so frequently because this is an accessible method in a reactive or impulsive situation without the availability of a weapon. Of note though, 
more than a quarter of sexual killers who strangled their victims did so even though a weapon was also used in the commission of the offense. This implies a choice to strangle, suggesting a behavioral preference, which is consistent with previous research, indicating that strangulation appears to be characteristic of sexual killing (Carter \& Hollin, 2010). This finding is possibly explained by the interpersonal nature of the act, which may be sexually gratifying (Arrigo \& Purcell, 2001). Present psychological data appear to support this hypothesis, given the combination of sexual entitlement beliefs and interpersonal difficulties.

In direct contrast to Salfati and Taylor's (2006) finding that intense violence was associated with sexual killing more than rape, results of this study revealed that evidence of disproportionate violence was actually recorded with greater frequency for sexual aggressors than for sexual killers. This finding invites critical discussion of continuum conceptualizations of sexual offending (Oliver et al., 2007; Proulx et al., 2007; Salfati \& Taylor, 2006). Most of the sexual aggressor sample had prior sexual convictions, indicative of an established behavioral pattern, and the presence of factors (weapon, stranger victim) that according to the hypothesized continuum of sexual violence should reduce the likelihood of the victim's survival. It could be hypothesized that weapon use and possibly stranger victims might be correlated with severity of violence in the offense and prior sexual offense convictions, which attract longer sentences in England and Wales and may therefore be artifacts of the sample selected. However, the purpose of identifying this unique group of sexual aggressors was to select a sample comparable with the sexual killers in terms of the seriousness of their offending as recognized in law, and in doing so the data suggest that factors previously thought to predict a fatal outcome may not be robust. Findings may be unextraordinary, given the aim of the present study to exclude instrumental killing and those cases of grievance driven/angry killing where sexual arousal is not closely associated with violence, to focus on a narrower definition of sexual killing. However, the results reported here emphasize the need to discriminate between cases of direct and indirect links between sexual arousal and killing.

The findings of this study are not without conceptual and methodological limitations. Operationalization of sampling is not consistent with previous research and, unexpectedly, might account for the discrepant findings in relation to the extant literature. Sexual killers who have been convicted but the sexual element of the crime remains undetected were not included, and there are limitations associated with the operationalization of the sexual killing sample. The aim of including only those who had engaged in post-mortem sexual interference was to exclude those who are most likely to poorly represent the sample but this is only a proxy for identifying those sexual killers for whom the act of killing forms an integral sexual element of the offense and further research might determine how reliable a marker this is. As postmortem sexual interference will not occur in all cases of sexual killing where there was nonetheless a direct link between sex and killing, the current sample may not be as representative of the sample as would be preferred.

The present study reported data from a sample of all sexual killers detained by Her Majesty's Prison Service who met the inclusion criteria, offending over a 45-year 
period from 1960 to 2005, and a sample of sexual aggressors age-matched to the sexual killer sample. Sampling from offenders referred to SOTP will have inevitably created a selection bias because there may be differences between offenders who are convicted and those who have evaded conviction. Indeed, rape is known to be underreported, and there may be a particular bias toward fewer convictions in intimate partner violence and other instances of rape against a known victim (Macdowall et al., 2013). In addition, this study would have excluded offenders who, at the point of criminal sentencing, would have received a hospital disposal. Personality disorders, particularly the anxious and avoidant types, appear to be characteristic of sexual killers but psychotic disorders are not thought to account for sexual killing (Kerr et al., 2013). Although there is a high prevalence of personality disorders in prison (e.g., Stewart, 2008), few studies on sexual killing have explicitly included mentally disordered perpetrators, and this should be addressed in future research.

Although not measured, it is possible that within the sample there was a high frequency of perpetrators for whom there is a sexual preference for coercive sex, which may be a factor in victim selection. The coding of some items from official records relied upon either offender disclosure or the presence of evidence in proxy of unambiguous information. For example, premeditation was scored if it was known that the offender took a weapon to the crime scene; however, this is clearly not a highly reliable indicator of planning. Premeditation may be underestimated for sexual killers considering the high proportion who did not use a weapon and the tendency to attempt to conceal sexual motives (Folino, 2000).

Psychometric assessments were completed when offenders entered the SOTP, which for prisoners serving long sentences may be after some considerable time in custody. Therefore, in addition to typical problems with self-report, there is a limitation in the extent to which assumptions can be made about the presence of self-reported psychological constructs at the time of the offense(s). This exploratory study provides an indication of the psychological similarities and differences of sexual killers and sexual aggressors at the point at which they enter a treatment program; to that extent, the results have clear practice implications for intervention. Given that some divergence was found in the psychometric profiles of sexual killers and sexual aggressors in this study, future research using a qualitative approach may be beneficial to identify whether there are cognitive distortions or schemas that are unique to sexual killers.

Due to changes in the psychometric measures adopted for use within SOTP over the timescale that offenders were assessed for treatment, it was not possible to include all of the variables that may be relevant to this area of research. In particular, it was not possible to measure the prevalence of sadistic personality disorder or sadistic sexual arousal patterns. Future research might address this issue as the present findings have shown some inconsistency in the sadistic behaviors of sexual killers compared with sexual aggressors, for example, the low frequency of humiliating acts in the sample of sexual killers. Given that humiliating behavior is thematic within sexual sadism research (Healey et al., 2013) and the present sample appeared more consistent with sadistic typologies of sexual killers than angry (Proulx et al., 2007), insofar as that they had all engaged in post-mortem sexual interference, and there was a low rate of 
overkill (Kerr et al., 2013), humiliation should then have been more characteristic of the sexual killers. Irrespective of the quality of the data sources, without a witness statement humiliation is likely to be unreliably accounted for, and its occurrence in sexual killing is likely to be underestimated. An alternative hypothesis to explore in future research is that within groups labeled either "sadistic," or more broadly, "deviant," there are yet further distinctions to better recognize the different functional roles of the act of killing. Sexual killers engaging in post-mortem sexual interference are likely to represent a subset of these "direct" cases, and whether they experience sexually sadistic interests warrants further research attention.

The conceptualization of sexual killers has important implications in forensic clinical practice. Interventions should not be indiscriminately recommended but should be tailored to take into account the differing treatment needs of different types of offenders (Clarke \& Carter, 2000; Hanson et al., 2002; Marshall \& Barbaree, 1990). Generally, treatment is provided for sexual killers alongside nonhomicide sexual offenders, despite a limited empirical basis for this; typical programs were not designed directly for this client group, and impact studies as well as validation of assessment tools are required (Carter et al., 2008; A. Hill et al., 2012; Tardif, Dassylva, \& Nicole, 2007). Evidence-based practice also depends on theoretical advancement, specifically the psychological mechanisms underlying models of offending behavior.

\section{Conclusion}

Few studies have questioned the validity of categorizing a killing as sexual when only an indirect link between killing and sexual arousal exists. A novel approach toward the identification of the sexual killer was adopted in this study, and data support the idea that there may be some utility in considering a targeted operationalization in sexual killing research. Steps toward identifying crime scene and psychological characteristics for a subgroup of sexual killers where there can be greater confidence of a direct link between killing and sexual arousal were taken. Findings have implications for policy makers assessing the suitability of risk assessments and interventions for those convicted of these extremely serious crimes. Therefore, a less ambiguous definition of sexual killing is necessary, and further research is needed that concentrates on those cases where there was a direct link between sexual arousal and killing.

\section{Acknowledgments}

The authors thank Russell A'Court, Christopher Kemp, and Joss Mistry from the Public Protection Unit for enabling access to the Public Protection Unit Database. Also, they thank the anonymous reviewers for extensive, detailed, and thought-provoking comments that have undoubtedly strengthened this article.

\section{Declaration of Conflicting Interests}

The author(s) declared no potential conflicts of interest with respect to the research, authorship, and/or publication of this article. 


\section{Funding}

The author(s) received no financial support for the research, authorship, and/or publication of this article.

\section{Note}

1. The data and materials used for this study are owned by the National Offender Management Service (NOMS), United Kingdom. Access to these may be provided subject to the written approval of a research proposal submitted to the NOMS National Research Committee.

\section{References}

Arrigo, B. A., \& Purcell, C. E. (2001). Explaining paraphilias and lust murder: Toward an integrated model. International Journal of Offender Therapy and Comparative Criminology, 45(1), 6-31. doi:10.1177/0306624X01451002

Beauregard, E., \& Martineau, M. (2013). A descriptive study of sexual homicide in Canada: Implications for police investigation. International Journal of Offender Therapy and Comparative Criminology, 57, 1454-1476. doi:10.1177/0306624X12456682

Beauregard, E., \& Mieczkowski, T. (2012). Risk estimations of the conjunction of victim and crime event characteristics on the lethal outcome of sexual assaults. Violence and Victims, 27, 470-486. doi:10.1891/0886-6708.27.4.470

Beauregard, E., \& Proulx, J. (2002). Profiles in the offending process of non-serial sexual murderers. International Journal of Offender Therapy and Comparative Criminology, 46(4), 386-399. doi:10.1177/0306624X02464002

Beech, A., Fisher, D., \& Ward, T. (2005). Sexual murderers' implicit theories. Journal of Interpersonal Violence, 20, 1366-1389. doi:10.1177/0886260505278712

Beech, A. R., Ward, T., \& Fisher, D. (2006). The identification of sexual and violent motivations in men who assault women: Implications for treatment. Journal of Interpersonal Violence, 21, 1635-1653. doi:10.1177/0886260506294242

Campos, E., \& Cusson, M. (2007). Serial killers and sexual murderers. In J. Proulx, E. Beauregard, M. Cusson, \& A. Nicole (Eds.), Sexual murderers: A comparative analysis and new perspectives (pp. 100-105). Chichester, UK: John Wiley.

Caprara, G. V. (1986). Indications of aggression: The Dissipation-Rumination Scale. Personality and Individual Differences, 7, 763-769. doi:10.1016/0191-8869(86)90074-7

Carter, A. J., \& Hollin, C. R. (2010). Characteristics of non-serial sexual homicide offenders: A review. Psychology, Crime \& Law, 16(1-2), 25-45. doi:10.1080/10683160802621933

Carter, A. J., \& Hollin, C. R. (2014). Assessment and treatment when sex is attached to a killing: A case study. In D. T. Wilcox, T. G. Garrett, \& L. Harkins (Eds.), Sex offender treatment: A case study approach to issues and interventions (pp. 286-304). Chichester, UK: Wiley-Blackwell.

Carter, A. J., Mann, R. E., \& Wakeling, H. C. (2008). Sexual killers and post mortem sexual interference offenders: Assessment, treatment and risk management. In A. J. R. Harris \& C. A. Pagé (Eds.), Sexual Homicide and Paraphilias: The Correctional Service of Canada's Experts Forum 2007 (pp. 167-212). Ottawa, Ontario: Correctional Service of Canada.

Chan, H., \& Heide, K. M. (2009). Sexual homicide: A synthesis of the literature. Trauma, Violence, \& Abuse, 10(1), 31-54. doi:10.1177/1524838008326478

Chéné, S., \& Cusson, M. (2007). Sexual murderers and sexual aggressors: Intention and situation. In J. Proulx, E. Beauregard, M. Cusson, \& A. Nicole (Eds.), Sexual murderers: A comparative analysis and new perspectives (pp. 72-86). Chichester, UK: John Wiley. 
Clarke, J., \& Carter, A. J. (2000). Relapse prevention with sexual murderers. In D. R. Laws, S. M. Hudson, \& T. Ward (Eds.), Remaking relapse prevention with sex offenders (pp. 389-401). London, England: SAGE.

Davis, M. H. (1980). A multi-dimensional approach to individual differences in empathy. JSAS Catalog of Selected Documents in Psychology, 10, 85-100.

Eysenck, S. B. G., \& Eysenck, H. J. (1978). Impulsivity and venturesomeness: Their position in a dimensional system of personality description. Psychological Reports, 43, 1247-1255. doi:10.2466/PR0.43.7.1247-1255

Fisher, D., \& Beech, A. R. (2007). Identification of motivations for sexual murder. In J. Proulx, E. Beauregard, M. Cusson, \& A. Nicole (Eds.), Sexual murderers: A comparative analysis and new perspectives (pp. 175-190). Chichester, UK: John Wiley.

Folino, J. O. (2000). Sexual homicides and their classification according to motivation: A report from Argentina. International Journal of Offender Therapy and Comparative Criminology, 44, 740-750. doi:10.1177/0306624X00446009

Gebhard, P., Gagnon, J., Pomeroy, W., \& Christensen, C. (1965). Sex Offenders: An Analysis of Types. New York, NY: Harper \& Row.

Grubin, D. (1994). Sexual murder. The British Journal of Psychiatry, 165, 624-629. doi:10.1192/ bjp.165.5.624

Häkkänen-Nyholm, H., Repo-Tiihonen, E., Lindberg, N., Salenins, S., \& Weizmann-Henelius, G. (2009). Finnish sexual homicides: Offense and offender characteristics. Forensic Science International, 188, 125-130. doi:10.1016/j.forsciint.2009.03.030

Hanson, R. K., Gizzarelli, R., \& Scott, H. (1994). The attitudes of incest offenders: Sexual entitlement and acceptance with children. Criminal Justice and Behavior, 21, 187-202.

Hanson, R. K., Gordon, A., Harris, A. J. R., Marques, J. K., Murphy, W., Quinsey, V. L., \& Seto, M. C. (2002). First report of the Collaborative Outcome Project on the effectiveness of psychological treatment for sex offenders. Sexual Abuse: Journal of Research and Treatment, 14, 169-194. doi:10.1023/A:1014624315814

Healey, J., Lussier, P., \& Beauregard, E. (2013). Sexual sadism in the context of rape and sexual homicide: An examination of crime scene indicators. International Journal of Offender Therapy and Comparative Criminology, 57, 402-424. doi:10.1177/03066 $24 \mathrm{X} 12437536$

Hill, A., Rettenberger, M., Habermann, N., Berner, W., Eher, R., \& Briken, P. (2012). The utility of risk assessment instruments for the prediction of recidivism in sexual homicide perpetrators. Journal of Interpersonal Violence, 27, 3553-3578. doi: $10.1177 / 0886260512447570$

Hill, M. S., \& Fischer, A. R. (2001). Does entitlement mediate the link between masculinity and rape-related variables? Journal of Counselling Psychology, 48, 39-50. doi:10.1037/00220167.48.1.39

James, J., \& Proulx, J. (2014). A psychological and developmental profile of sexual murderers: A systematic review. Aggression and Violent Behavior, 19, 592-607. doi:10.1016/j. avb.2014.08.003

Kerr, K. J., Beech, A. R., \& Murphy, D. (2013). Sexual homicide: Definition, motivation and comparison with other forms of sexual offending. Aggression and Violent Behavior, 18(1), 1-10. doi:10.1016/j.avb.2012.05.006

Knight, R. A., \& Prentky, R. A. (1990). Classifying sexual offenders: The development and corroboration of taxonomic models. In W. L. Marshall, D. R. Laws, \& H. E. Barbaree (Eds.), Handbook of Sexual Assault: Issues, Theories, and Treatment of the Offender (pp. 23-52). New York, NY: Plenum. 
Koch, J., Berner, W., Hill, A., \& Briken, P. (2011). Sociodemographic and diagnostic characteristics of homicidal and nonhomicidal sexual offenders. Journal of Forensic Sciences, 56, 1626-1631. doi:10.1111/j.1556-4029.2011.01933.x

Kraemer, G. W., Lord, W. D., \& Heilbrun, K. (2004). Comparing single and serial homicide offenses. Behavioral Sciences \& The Law, 22, 325-343. doi:10.1002/bsl.581

Langevin, R. (2003). A study of the psychosexual characteristics of sex killers: Can we identify them before it is too late? International Journal of Offender Therapy and Comparative Criminology, 47, 366-382.

Langevin, R., Ben-Aron, M. H., Wright, P., Marchese, V., \& Handy, L. (1988). The sex killer. Sexual Abuse: A Journal of Research and Treatment, 1, 263-301. doi:10.1177/107906328800100206

Levenson, H. (1974). Activism and powerful other: Distinctions within the concept of internalexternal control. Journal of Personality Assessment, 38, 377-383. doi:10.1080/00223891. 1974.10119988

Liem, M. C. A., \& Pridemore, W. A. (2012). Handbook of European Homicide Research: Patterns, Explanations, and Country Studies. New York, NY: Springer.

Macdowall, W., Gibson, L. J., Tanton, C., Mercer, C. H., Lewis, R., Clifton, S., .. .Wellings, K. (2013). Lifetime prevalence, associated factors, and circumstances of non-volitional sex in women and men in Britain: Findings from the third National Survey of Sexual Attitudes and Lifestyles (Natsal-3). The Lancet, 382, 1845-1855. doi:10.1016/S0140-6736(13)62300-4

Maniglio, R. (2010). The role of deviant sexual fantasy in the etiopathogenesis of sexual homicide: A systematic review. Aggression and Violent Behavior, 15, 294-302. doi:10.1016/j. avb.2010.02.001

Marshall, W. L., \& Barbaree, H. E. (1990). Outcome of comprehensive cognitive-behavioral treatment programs. In W. L. Marshall, D. R. Laws, \& H. E. Barbaree (Eds.), Handbook of sexual assault: Issues, theories, and treatment of the offender. New York, NY: Plenum Press.

Meloy, J. R. (2000). The nature and dynamics of sexual homicide: An integrative review. Aggression and Violent Behavior, 5(1), 1-22. doi:10.1016/S1359-1789(99)00006-3

Mieczkowski, T., \& Beauregard, E. (2010). Lethal outcome in sexual assault events: A conjunctive analysis. Justice Quarterly, 27, 332-361. doi:10.1080/07488820902960105

Milsom, J., Beech, A. R., \& Webster, S. D. (2003). Emotional loneliness in sexual murderers: A qualitative analysis. Sexual Abuse: A Journal of Research and Treatment, 15, 285-296. doi:10.1023/A:1025095927047

Nicole, A., \& Proulx, J. (2007). Sexual murderers and sexual aggressors: Developmental paths and criminal history. In J. Proulx, E. Beauregard, M. Cusson, \& A. Nicole (Eds.), Sexual murderers: A comparative analysis and new perspectives (pp. 29-50). Chichester, UK: John Wiley.

Offending Behavior Programmes Unit. (1995a). Rape Myths Scale. Unpublished manuscript, National Offender Management Service, Ministry of Justice, London, England.

Offending Behavior Programmes Unit. (1995b). Women Are Deceitful Scale. Unpublished manuscript, National Offender Management Service, Ministry of Justice, London, England.

Oliver, C. J., Beech, A. R., Fisher, D., \& Beckett, R. (2007). A comparison of rapists and sexual murderers on demographic and selected psychometric measures. In J. Proulx, E. Beauregard, M. Cusson, \& A. Nicole (Eds.), Sexual murderers: A comparative analysis and new perspectives (pp. 159-173). Chichester, UK: John Wiley.

Perneger, T. V. (1998). What's wrong with Bonferroni adjustments. BMJ: British Medical Journal, 316, 1236-1238. 
Proulx, J., Cusson, M., \& Beauregard, E. (2007). Sexual murder: Definitions, epidemiology and theories. In J. Proulx, E. Beauregard, M. Cusson, \& A. Nicole (Eds.), Sexual murderers: A comparative analysis and new perspectives (pp. 9-28). Chichester, UK: John Wiley.

Proulx, J., \& Sauvêtre, N. (2007). Sexual murderers and sexual aggressors: Psychopathological considerations. In J. Proulx, E. Beauregard, M. Cusson, \& A. Nicole (Eds.), Sexual murderers: A comparative analysis and new perspectives (pp. 51-69). Chichester, UK: John Wiley.

Rallings, M., \& Webster, S. D. (2001). The psychometric properties of the HMPS SOTP Psychometric Battery. Unpublished manuscript.

Ressler, R. K., Burgess, A. W., \& Douglas, J. E. (1988). Sexual homicide: Patterns and motives. New York, NY: The Free Press.

Russell, D., Peplau, L. A., \& Cutrona, C. A. (1980). The revised UCLA Loneliness Scale: Concurrent and discriminant validity evidence. Journal of Personality and Social Psychology, 39, 472-480.

Salfati, G., \& Taylor, P. (2006). Differentiating sexual violence: A comparison of sexual homicide and rape. Psychology, Crime \& Law, 12, 107-125. doi:10.1080/10683160500036871

Schlesinger, L. B. (2007). Sexual homicide: Differentiating catathymic and compulsive murders. Aggression and Violent Behavior, 12, 242-256. doi:10.1016/j.avb.2006.09.007

Soothill, K., \& Francis, B. (2012). Homicide in England and Wales. In M. C. A. Liem \& W. A. Pridemore (Eds.), Handbook of European Homicide Research: Patterns, Explanations, and Country Studies (pp. 287-300). New York, NY: Springer.

Stefanska, E. B., Carter, A. J., Higgs, T., Bishopp, D., \& Beech, A. R. (2015). Offense pathways of non-serial sexual killers. Journal of Criminal Justice, 43, 99-107. doi:10.1016/j. jcrimjus.2015.01.001

Stewart, D. (2008). The problems and needs of newly sentenced prisoners: Results from a national survey. London, England: Ministry of Justice.

Tardif, M., Dassylva, B., \& Nicole, A. (2007). Psychotherapeutic and psychodynamic issues with sexual murderers. In J. Proulx, E. Beauregard, M. Cusson, \& A. Nicole (Eds.), Sexual murderers: A comparative analysis and new perspectives (pp. 213-228). Chichester, UK: John Wiley.

Thornton, D. (2007). Scoring guide for risk matrix 2000.9/SVC: February 2007 Version. Retrieved from http://www.birmingham.ac.uk/Documents/college-les/psych/RM2000scoringinstructions. pdf

Underhill, J., Wakeling, H. C., Mann, R. E., \& Webster, S. (2008). Male sexual offenders' emotional openness with men and women. Criminal Justice and Behavior, 35, 1156-1173. doi: $10.1177 / 0093854808320268$

Wakeling, H. C., \& Barnett, G. D. (2011). Measuring grievance thinking in sexual offenders: The revised Dissipation-Rumination Scale. Journal of Sexual Aggression, 17, 273-289. doi:10.1080/13552600.2010.495422

Wakeling, H., Beech, A. R., \& Freemantle, N. (2013). Investigating treatment change and its relationship to recidivism in a sample of 3773 sex offenders in the UK. Psychology, Crime \& Law, 19, 233-252. doi:10.1080/1068316X.2011.626413

Webster, S. D., Mann, R. E., Thornton, D., \& Wakeling, H. C. (2007). Further validation of the short self-esteem scale with sexual offenders. Legal and Criminological Psychology, 12, 207-216. doi:10.1348/135532506X114347 